\title{
PROJECT MANAGEMENT SIMULATION WITH PTB PROJECT TEAM BUILDER
}

\author{
Avraham Shtub \\ Faculty of Industrial Engineering and Management \\ Technion-Israel Institute of Technology \\ Haifa 32000, ISRAEL
}

\begin{abstract}
This paper presents a new tool for the teaching professional and students of Project Management - a tool that can easily integrate traditional teaching based on any course or textbook available in the market. The Project Team Builder software tool combines an interactive, dynamic case study and a simple yet effective Project Management System. The Project Team Builder (PTB) won the Project Management Institute (PMI) 2008 Professional Development Product of the Year Award. It is designed to support teaching of project management at the graduate and undergraduate level as well as for training professionals. PTB is the basis of a new book published by Springer "Project Management Simulation with PTB Project Team Builder". The PTB provides an environment for hands-on experience in project scheduling, resource and budget planning, risk management and project control.
\end{abstract}

\section{INTRODUCTION}

Confucius said: "I hear and I forget. I see and I remember. I do and I understand."

This is the essence of the book "Project management simulation with PTB project team builder" (Shtub 2010), we have to experience some things ourselves in order to really understand it. In his article, James I. Grieshop (Grieshop 1987) stated that: "Games and simulations (ranging from role playing to case studies, from guided fantasy to problem solving) have become widely recognized methods for instruction and learning. Since the early work in the United States in the late 1950s and in Europe in the late 1960s, gaming/simulation has become increasingly important to training and decision-making processes in academic settings as well as in business, the military, and the social sciences."

Grieshop (1987) listed some of the benefits of games and simulations:

1. Emphasize questioning over answering on the part of players.

2. Provide opportunities to examine critically the assumptions and implications that underlie various decisions.

3. Expose the nature of problems and possible solution paths.

4. Create an environment for learning that generates discovery learning.

5. Promote skills in communicating, role-taking, problem solving, leading, and decision-making.

6. Increase the motivation and interest in a subject matter.

Grieshop (1987) states that evidence is offered for:

1. increased retention,

2. energizing the learning process,

3. facilitating an understanding of the relationships between areas within a subject matter. 


\section{Shtub}

Since the publication of Grieshop's work in 1987, simulation has been used for training in a wide range of fields: in Engineering (IJEE 2009), in management of quality, in supply chain management (Knoppen and Sáenz 2007), and in process re-engineering (Smeds and Riis 1998, Thoben et al. 2007). Empirical research (Millians 1999, Ruben 1999, Randel et al. 1992, Meijer et al. 2006, 569-583) expanded our knowledge of this training approach presenting new ways of understanding and implementing simulation for training. Today it is widely accepted that learning through simulation is based on three pillars (Keys 1976, Kolb 1984, Kirby 1992):

1. learning from content - the dissemination of new ideas, principles, or concepts.

2. learning from experience - an opportunity to apply content.

3. learning from feedback - the result of actions taken and the relationship between the actions and performance.

A well designed simulator supports a process of action-based learning. Instead of talking about different ways of doing things, simulators offer an opportunity to try different ways of doing things without risking the consequences of doing so in the real world.

Simulators create an environment that requires the participant to be involved in a meaningful task. The source of learning is what the participants do rather than what they are told by the trainer.

Thompson, Purdy and Fandt (1997) list the advantages of using simulations as a learning tool:

1. Simulators are characterized as tools enabling the acquisition of practical experience and acceptance of an immediate response of the learned system to the user's decisions and actions.

2. Simulators offer a realistic model of the interdependence of decisions that the trainee makes.

3. Simulation-based training reduces the gaps between the learning environment and the "real" environment.

4. Simulators facilitate training in situations that are difficult to obtain in the "real world".

5. Simulations promote active learning, especially at the stage of debates that arise because of the complexity, interconnectedness, and novelty of decision-making.

Wolfe (1993) notes that simulations develop critical and strategic thinking skills. He claims that the skills of strategic planning and thinking are not easy to develop and the advantage of simulators is that they provide a strong tool for dealing with this problem.

An important development in the design of training simulators is to provide the learners with automatic or semi-automatic feedback on their progress. A learning history mechanism was used in several simulation-based teaching tools. The user of these systems obtains access to past states and decisions and to the consequences of these decisions. Learning histories encourage the users to monitor their behavior and reflect on their progress (Carroll et al. 1996, Guzdial et al. 1996). Learning histories enables analysis of the decision-making process as opposed to analysis of results only and therefore it is very effective because the direct influence on the user's actions can be seen. For example, learning history is used as a quality improvement tool for programmers (Prechelt 2001).

The most basic view of history recording and inquiry is the temporal sequence of actions and events. In its simplest form, user actions are logged and recorded, and are then accessible in various ways for recovery and backtracking purposes (Vargo, Brown, and Swierenga 1992). Such a mechanism is used as "undo". Several recovery mechanisms have been developed using the simple undo/undo or undo/redo (e.g., Archer, Conway, and Schneider 1984).

Parush, Hamm, and Shtub (2002) described simulation-based teaching of the order fulfillment process in a manufacturing context, using the Operations Trainer (Shtub 1999, Shtub 2001) with a built-in learning history recording and inquiry mechanism. The study addressed a basic question:

Can history recording and inquiry affect the transfer of what was learnt with the simulator? 


\section{Shtub}

The findings showed that with the learning history recording and inquiry available to users, better performance was obtained during the learning process itself. In addition, the performance of learners with the history mechanism was better when transferred to a different context, compared to learners without the history mechanism.

The studies reviewed above demonstrated that having an opportunity to review learning history had a positive impact on learning. However, these studies did not examine if the mode of history recording could have an impact on learning. History recording can be done either by automatic mechanism or by learner control. In automatic history recording, the training system such as the simulator determines when to record a given state in the learning process. These recording points are pre-determined by the simulator designer or the instructor that prepares the training program. In such a situation, the learner is not involved in the decision when to keep a specific state in the learning process. In contrast, in a learner-controlled mode, the learner determines if and when to keep a specific state in the learning process. It was shown however that giving the learners some control over the learning environment by letting them actively construct the acquired knowledge produces better learning (Cuevas et al. 2004).

The successful use of a simulator for teaching project management was reported in several studies (Davidovitch, Parush, and Shtub 2006, 2008, 2009). The simulator - an early generation of PTB called the Project Management Trainer (PMT) was used in those studies as a teaching aid designed to facilitate the learning of project management in a dynamic, stochastic environment. The research focused on the effect of the history recording mechanism on the learning process. Two types of history mechanisms were tested: the automatic history mechanism, in which predefined scenario's states are always saved, and the manual history mechanism, in which the trainee had to show an active involvement and to save selected states manually. In Davidovitch, Parush, and Shtub (2006) the study focused on how project managers' decisions to record the history affected the learning process and on the effects of history inquiry when the ability to restart the simulation from a past state is not enabled. In Davidovitch, Parush, and Shtub (2008) the study focused on the forgetting phenomenon and on how the length of a break period and history mode affected the learning, forgetting, and relearning (LFR) process. Both studies revealed that history recording improved learning; furthermore, with the manual history mechanism learners achieved the best results.

The issue of a simulator's functional fidelity is also of great interest. The fidelity of a simulator is a measure of its deviation from the real situation; it has three dimensions: perceptual, functional and model fidelity. Perceptual fidelity refers to the level of realism it evokes in terms of its look and feel relative to the real system. Functional fidelity refers to the way users or trainees use and control the simulation, its behavior and responses to user actions. Finally, model fidelity refers to the extent to which the mathematical or logical model underlying the simulation is close to the real processes and phenomena.

The fidelity of the simulator has been recognized as a critical factor influencing the transfer of learning (Alessi 1988). In order to provide a higher level of functional fidelity, the PTB simulator includes two functionalities: the ability to control the level of human resources and the ability to control the execution of the tasks. These functionalities are made available to trainees as part of the scenario development. The ability to control the level of human resources refers to the decision to hire or fire employees in accordance with the changing demand for resources during the project's execution; the project manager can control the number of employees in the project in order to match availability to needs. The ability to control the execution of the tasks refers to the decision to split tasks during execution - a task can begin, stop for a while and continue later.

Davidovitch, Parush, and Shtub (2009) found that higher fidelity improved performances in the learning phase and in the transfer phase to a different scenario.

\section{PRINCIPLES OF PTB}

The Project Team Builder (PTB) is a training aid designed to facilitate the training of project management in a dynamic, stochastic environment. There are five process groups in the 2008 edition of the PMBOK (that include a total of 42 processes): 
1. Initiating Process Group

2. Planning Process Group

3. Executing Process Group

4. Monitoring and Controlling Process Group

5. Closing Process Group

The PTB supports training in three groups of processes: planning processes, executing processes and monitoring and controlling processes (these three groups of processes include 38 processes out of the 42 but the PTB does not support training in all these 38 processes). The PMBOK stresses the interactions between these three process groups and the PTB is designed to facilitate the integration of these processes during training by using the following principles:

- A simulation approach - the PTB simulates one or more projects or several work packages of the same project. The simulation is controlled by a simple user interface and no knowledge of simulation or simulation languages is required.

- A case study approach - the PTB is based on a simulation of case studies called scenarios. Each case study is a project or a collection of projects performed in a dynamic stochastic environment. In some scenarios the projects are performed under schedule, budget and resource constraints. The details of these case studies are built into the simulation while all the data required for analysis and decision-making is easily accessed by the user interface.

- A dynamic approach - the case studies built into the PTB are dynamic in the sense that the situation changes over time. A random effect is introduced to simulate the uncertainty in the environment, and decisions made by the user cause changes in the state of the system simulated.

- A model-based approach - a decision support system is built into the PTB. This system is based on project management concepts. The model base contains well-known models for scheduling, budgeting, resource management and monitoring and control. These models can be consulted at any time.

- To support decision-making further, a database is built into the PTB. Data on the current state of the simulated system is readily available to the users; it is possible to use the data as input to the models in the model base to support decision-making. Furthermore, using special history mechanisms the user can access data on his past decisions and their consequences.

- User friendliness and GUI - the PTB is designed as a teaching and training tool. As such, its Graphic User Interface (GUI) is friendly and easy to learn. Although quite complicated scenarios can be simulated, and the decision support tools are sophisticated, a typical user can learn how to use the PTB within an hour.

- An integrated approach - several projects can be managed simultaneously on the PTB. These projects can share the same resources and a common cash flow.

- Integration of processes: planning processes, executing processes and monitoring and controlling processes. All these processes are performed simultaneously in a dynamic stochastic environment.

- Integration with commercial project management tools - the PTB is integrated with Microsoft Project so that the users can import real projects from Microsoft Project and simulate these projects or export the data to Microsoft Project to analyze the scenario and to support its decisions with tools that are commercially available.

The PTB provides a supporting setting for training in Project Management. The concept of a simulation-based training environment with a built-in learning history recording and inquiry mechanism is employed in the PTB. The PTB can be used as a stand-alone system as it contains models for scheduling, budgeting, resource management, cash management, monitoring and control. The PTB can also be used 


\section{Shtub}

with Microsoft Project to plan the project, to monitor and to control it by transferring information from the Project Team Builder (PTB) and analyzing it using Microsoft Project.

\section{SCENARIOS IN PTB}

The PTB is available in two versions - the individual version and a commercial version. The individual version comes with several predefined scenarios designed to introduce the user to different aspects of project management. All these predefined scenarios are designed for a single user (as the individual version of PTB does not support team learning). The individual version that accompanies the book "Project management simulation with PTB project team builder" comes with two sets of scenarios. One set is discussed in detail and is used as a basis for a tutorial; the other set of (more advanced) scenarios is designed to help the reader practice his skills and to support self-learning. The commercial version of PTB comes with a scenario generator with which the instructor can generate specific scenarios (http://www.sandboxmodel.com/). The instructor can generate scenarios based on pre-specified teaching objectives (e.g. teaching risk management, resource constraint project scheduling or teaching cash flow management in projects). The instructor can also generate scenarios based on real projects performed in the organization in which the training takes place; in this case it is possible to develop scenarios based on data from real projects imported from commercial project management software like Microsoft Project.

\subsection{The (simple) Tutorial Scenarios}

A set of four scenarios is used as a basis for the tutorial in the book "Project management simulation with PTB project team builder"; the tutorial is focusing on simple principles of project management. Information on each of these scenarios is available in the general project information screen (see Figure 1):

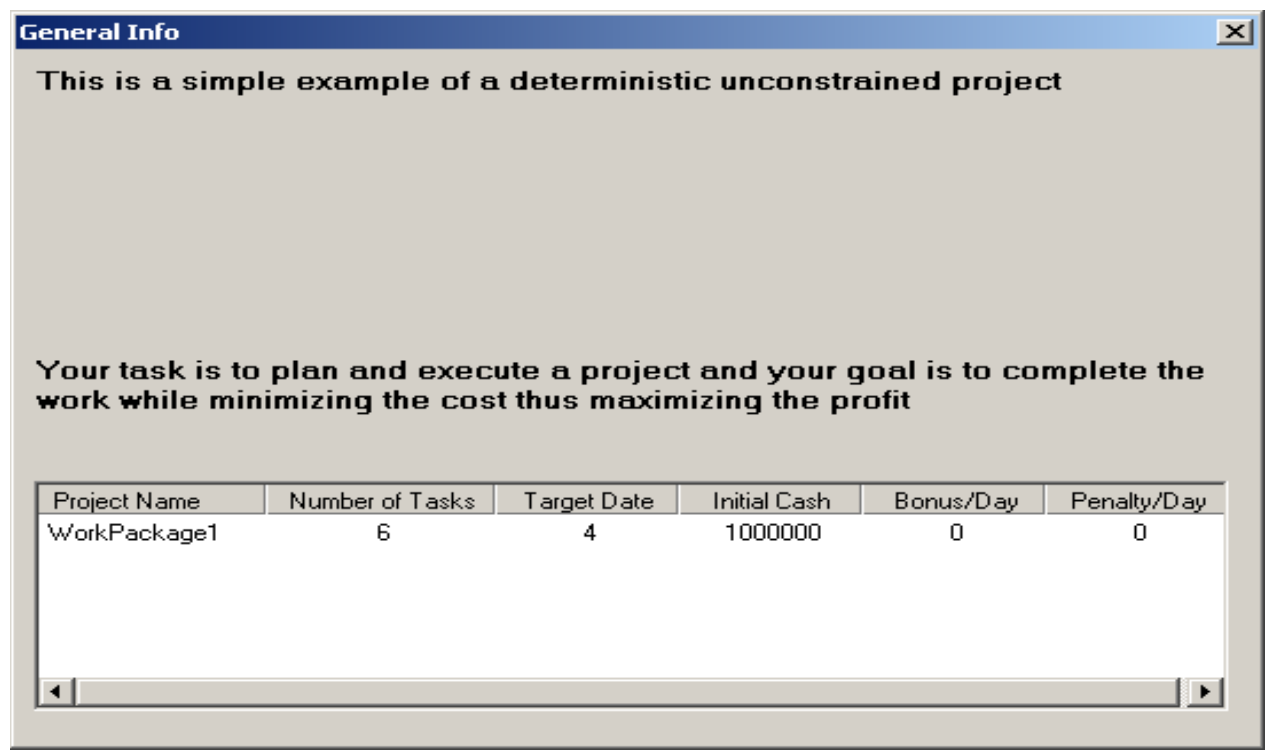

Figure 1: the general project information screen

Each scenario has a due date (or a target date) by which the project should finish. In these simple scenarios there is no penalty for late completion and no bonus for early completion. In the advanced scenarios (see 3.2 below) a bonus and penalty are specified for each scenario.

The four tutorial scenarios simulate one building block of a project known as a work package (work package 1 in the screen shot below) with six tasks. Work package 1 consists of tasks related to the management of the project (task A), tasks related to software development and testing (tasks B, and C) and 


\section{Shtub}

tasks related to hardware development and testing (tasks D, E, and F). Each task has an identification number; for example task $\mathrm{A}$ is task number 1 and task $\mathrm{F}$ is task number 6.

There are precedence relations between some tasks as outlined in the following table (see Figure 2):

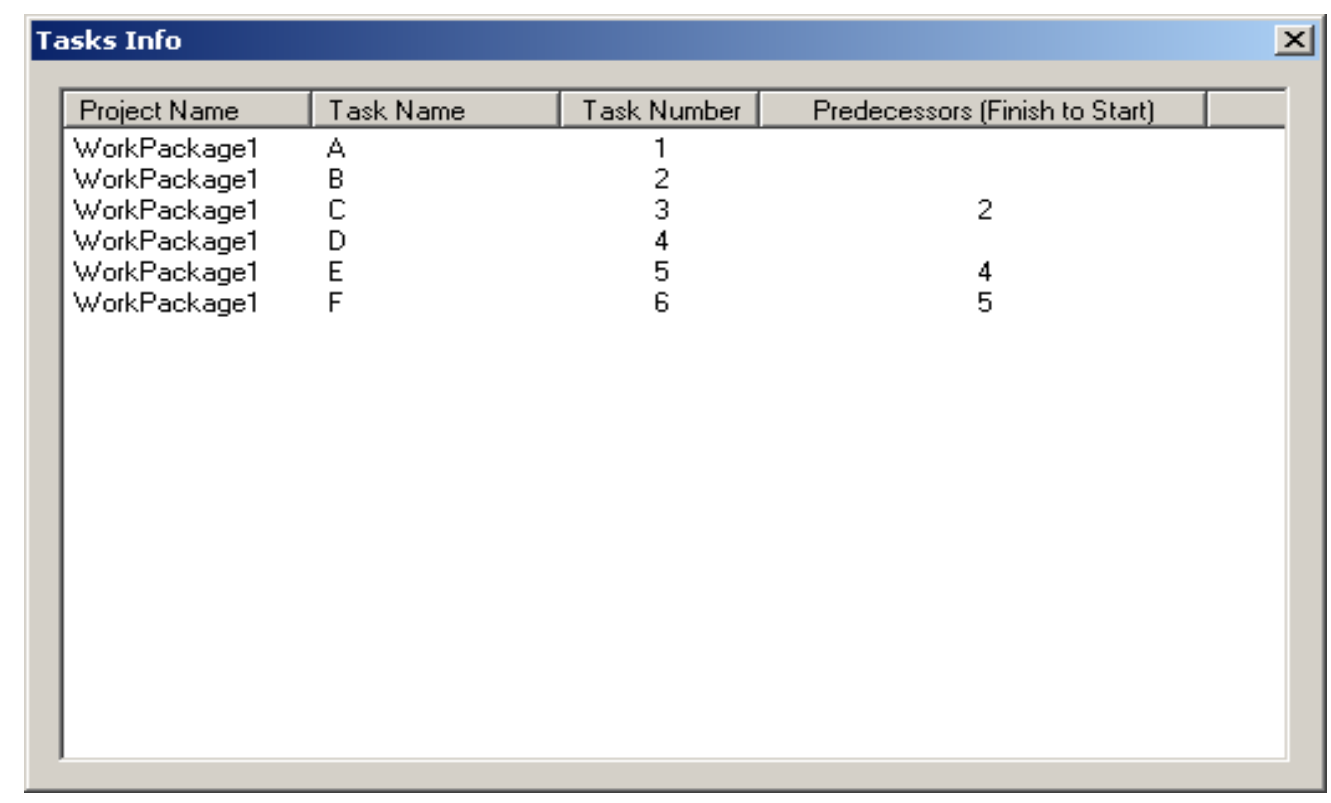

Figure 2: the task information screen

The precedence relations between the tasks of work package 1 are of the finish-to-start type. These precedence relations represent a situation in which a task cannot start till all its predecessors are finished. For example tasks A and B can start as soon as the project starts since both have no predecessors, but task $\mathrm{C}$ can start only after its predecessor B is finished.

In the tutorial scenarios there is only one way to perform each task (in project management this is called a mode). In the advanced scenarios some tasks can be performed in more than one mode, for example a task can be done in-house or by a subcontractor and the user must select one of the two modes for this task. Mode selection is an important decision in project management as the mode defines the type of resources required to perform the task, the required quantity of each resource type, and the expected duration of the task. For example task A (task 1) is a single mode task (see Figure 3).

The task duration in this example is deterministic, i.e., it is known for sure. Therefore all three estimates (the optimistic time, the most likely time and the pessimistic time) are the same. In an uncertain environment the duration of the task performed at a specific mode is presented by a distribution as depicted in the example of task C (see Figure 4).

In this case the optimistic time is 1 day or one time period (we will assume that time periods in PTB are in days), the most likely time is 2 time periods and the pessimistic time is 9 time periods. During the execution of the project the PTB simulator will randomly generate the actual duration from the above distribution.

The same screen that lists possible modes presents additional information about the task. To perform a task in any given mode resources may be required. In the example above, task $\mathrm{C}$ requires one unit of a resource called worker during its execution. The actual cost of the worker performing task $\mathrm{C}$ depends on the task's actual duration that may be deterministic or randomly generated by PTB. The fixed cost of the task represents the cost that is independent of the task's actual duration. For example, a fixed cost is the cost of material required to perform the task. The number of resource units required of each resource type is de- 
fined by the mode - the assumption is that the task cannot be executed unless all the required resources are available in the required quantities.

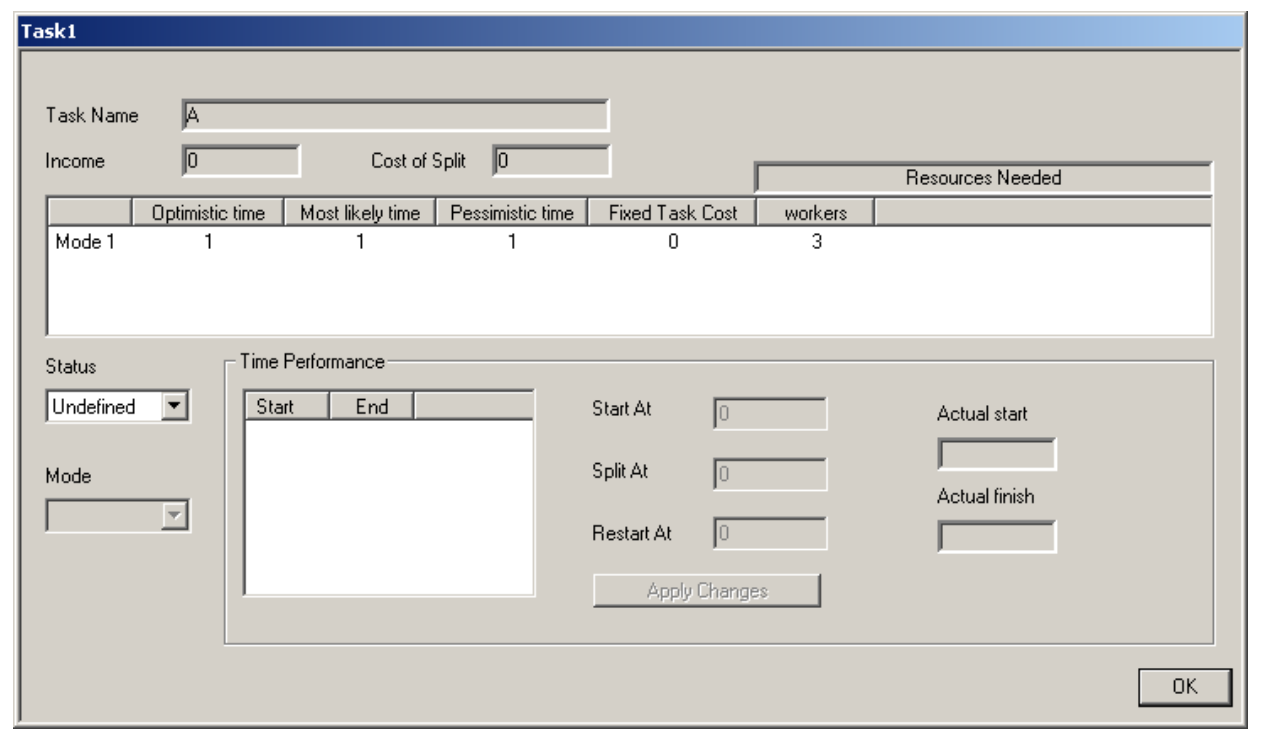

Figure 3: deterministic task planning screen

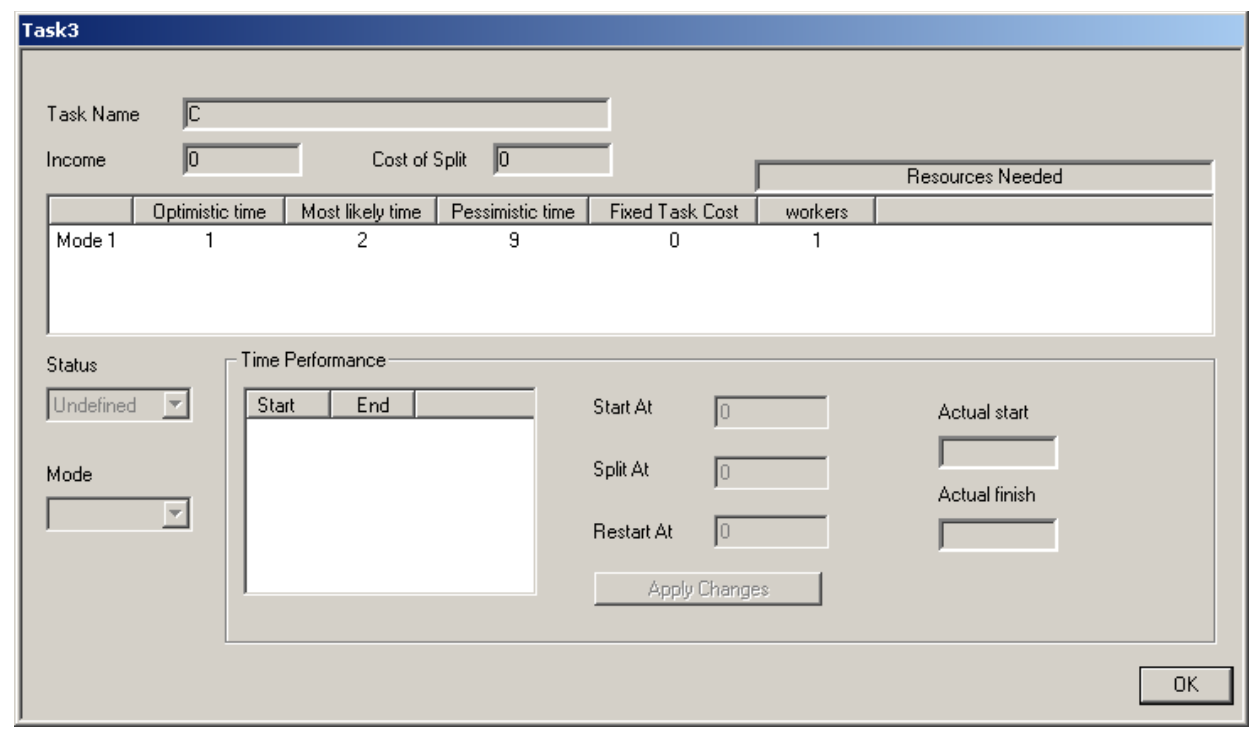

Figure 4: stochastic task planning screen

In addition to mode information, each task may have an income associated with its completion. This is important information for cash flow management, when the user may have to schedule tasks that generate income as early as possible to avoid a situation in which the project is terminated prematurely due to bankruptcy — lack of cash.

The PTB provides information about the resources required to perform the tasks. Each resource has a specific name. The availability of each resource (number of units) may be fixed in some scenarios or may vary by allowing the user to hire and fire workers (or any other resource). The availability of resources may be deterministic (each resource unit is available every time period with complete certainty) or stochastic (each resource unit is available every time period with a given probability). The cost of resources 
is an important factor for project planning. This cost of resources includes the cost per time period (or per day) that the resource is performing a task and for some resources it may include the cost per time period that the resource is idle (not assigned to any task) (see Figure 5):

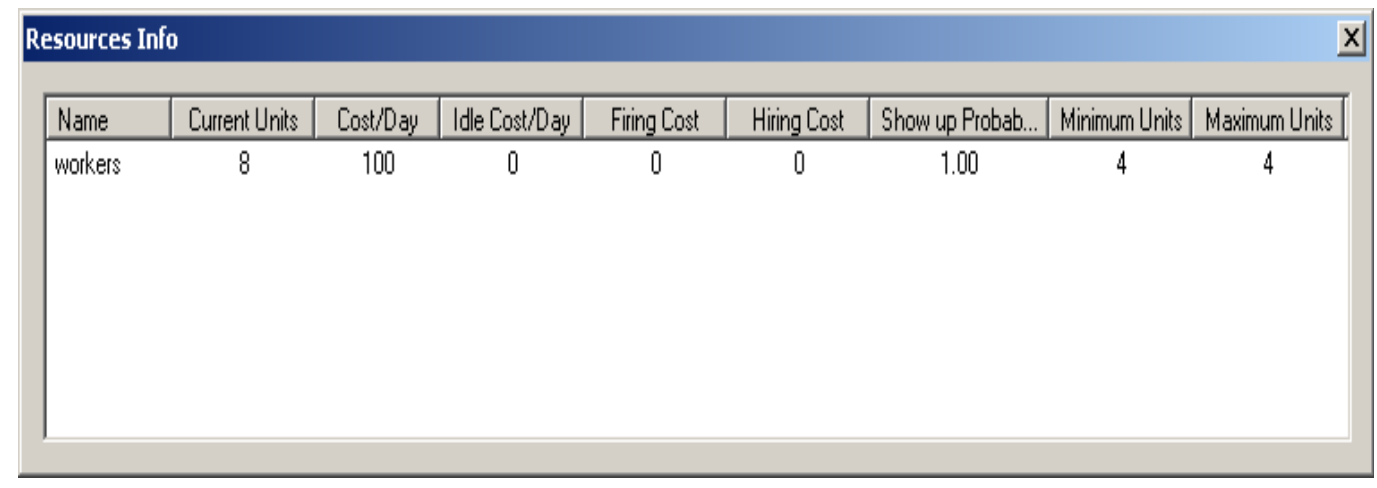

Figure 5: the resources information screen with a single resource type

Planning simple projects is a process in which the start time of each task is set, taking into account the precedence relations between tasks, to create a plan that achieves the project goals and does not violate resource, cash and other constraints.

Once a plan is developed the PTB is used to simulate the execution of the plan and let the user manage the project in a dynamic, stochastic environment similar to the environment in which real projects are performed.

The four tutorial scenarios are based on work package 1 as explained above. The tutorial scenarios are designed to train the user in the following situations:

1. Unconstrained Deterministic Scheduling (UDS) - this is the simplest problem in project planning. Resources are plenty and there is no need to hire any additional resources or to delay tasks due to the shortage of resources. A tool called the Gantt chart is built into the PTB to support this planning activity.

2. Unconstrained Stochastic Scheduling (USS) - in this problem resources are also available in sufficient quantities and there is no need to hire any additional resources or to delay tasks due to the shortage of resources but the exact duration of each task is not known. Due to the uncertainty there is a need to monitor and control the project during its execution and to take corrective actions when needed. In the Gantt chart the duration of each activity is the average of its three point time estimate (the average of the optimistic time, most likely time and the pessimistic time rounded to the nearest integer). The Gantt chart is used for planning and a control system is used for monitoring and control.

3. Resource Constrained Deterministic Scheduling (RCDS) - this is a problem in project planning in which resources are limited in availability and there might be a need to delay tasks due to the shortage of resources.

4. Resource Constrained Stochastic Scheduling (RCSS) - this is a problem in project management in which resources are limited in availability and there might be a need to delay tasks due to the shortage of resources. In addition the exact duration of each task is not known. Due to the uncertainty there is a need to monitor and control the project during its execution and to take corrective actions when needed.

\subsection{Advanced (challenging) Scenarios}

In addition to the tutorial scenarios the individual version of the Project Team Builder (PTB) that accompanies the book "Project management simulation with PTB project team builder" comes with a set of four 
advanced scenarios. All the advanced scenarios are based on a real project - The Electrical Distribution Substation Project.

An electrical distribution substation is a subsidiary station of an electricity generation, transmission and distribution system where voltage is transformed from high to low using transformers (Wikipedia). It is uneconomical to directly connect electricity consumers to the high-voltage main transmission network, so the distribution station reduces voltage to a value suitable for local distribution. The main issues in planning an electrical distribution substation project are time and cost. A good plan attempts to strike a balance between these two.

The design effort consists of the selection of a proper location, the selection of equipment, facility layout design, mechanical design, electrical design and the design of the building in which the electrical distribution substation is housed.

In the electrical design, incoming lines will almost always have a disconnect switch and a circuit breaker. A disconnect switch is used to provide isolation, since it cannot interrupt load current. A circuit breaker is used as a protection device to interrupt faulty currents automatically, and may be used to switch loads on and off. Both switches and circuit breakers may be operated locally (within the substation) or remotely from a supervisory control center.

Once past the switching components, the lines of a given voltage connect to one or more buses. These are sets of bus bars, usually in multiples of three, since three-phase electrical power distribution is largely universal around the world.

The arrangement of switches, circuit breakers and buses used affects the cost and reliability of the substation. Substations feeding only a single industrial load may have minimal switching provisions, especially for small installations.

Once having established buses for the various voltage levels, transformers may be connected between the voltage levels. These will again have a circuit breaker, much like transmission lines, in case a transformer has a fault (commonly called a 'short circuit').

Along with this, a substation always has control circuitry needed to command the various breakers to open in case of the failure of some component.

In this project, the electrical distribution substation is connected to a generator as a backup. The design is available and a master plan for the project was developed. The main tasks in the master plan are listed in the tasks info. field along with a short description of each task and the preceding tasks.

The project has a due date and late completion will result in a penalty. A bonus for early completion of the project will be paid if the project is finished before its due date.

Three groups of workers are assigned to the project. The number of workers in each group may vary as well as the costs. The workers in each group are having identical skills as summarized in the resources information (see Figure 6):

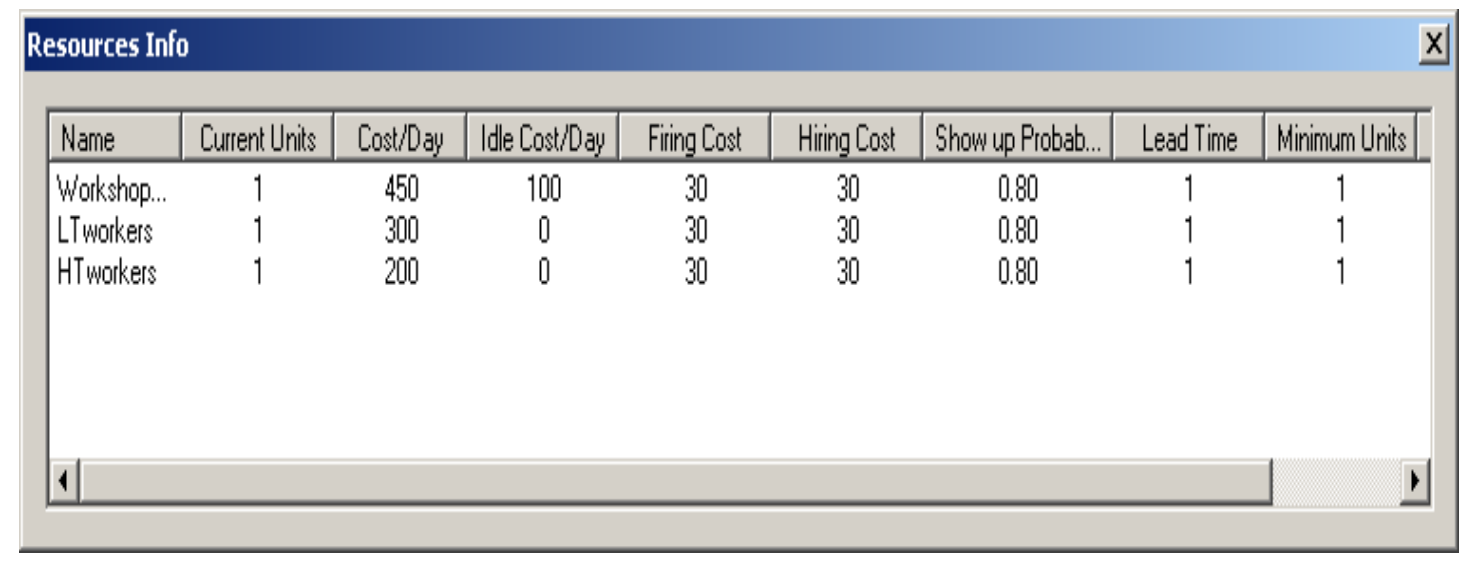

Figure 6: the resources information screen with multiple resource types 
The Electrical distribution substation Project consists of 12 tasks (see Figure 7):

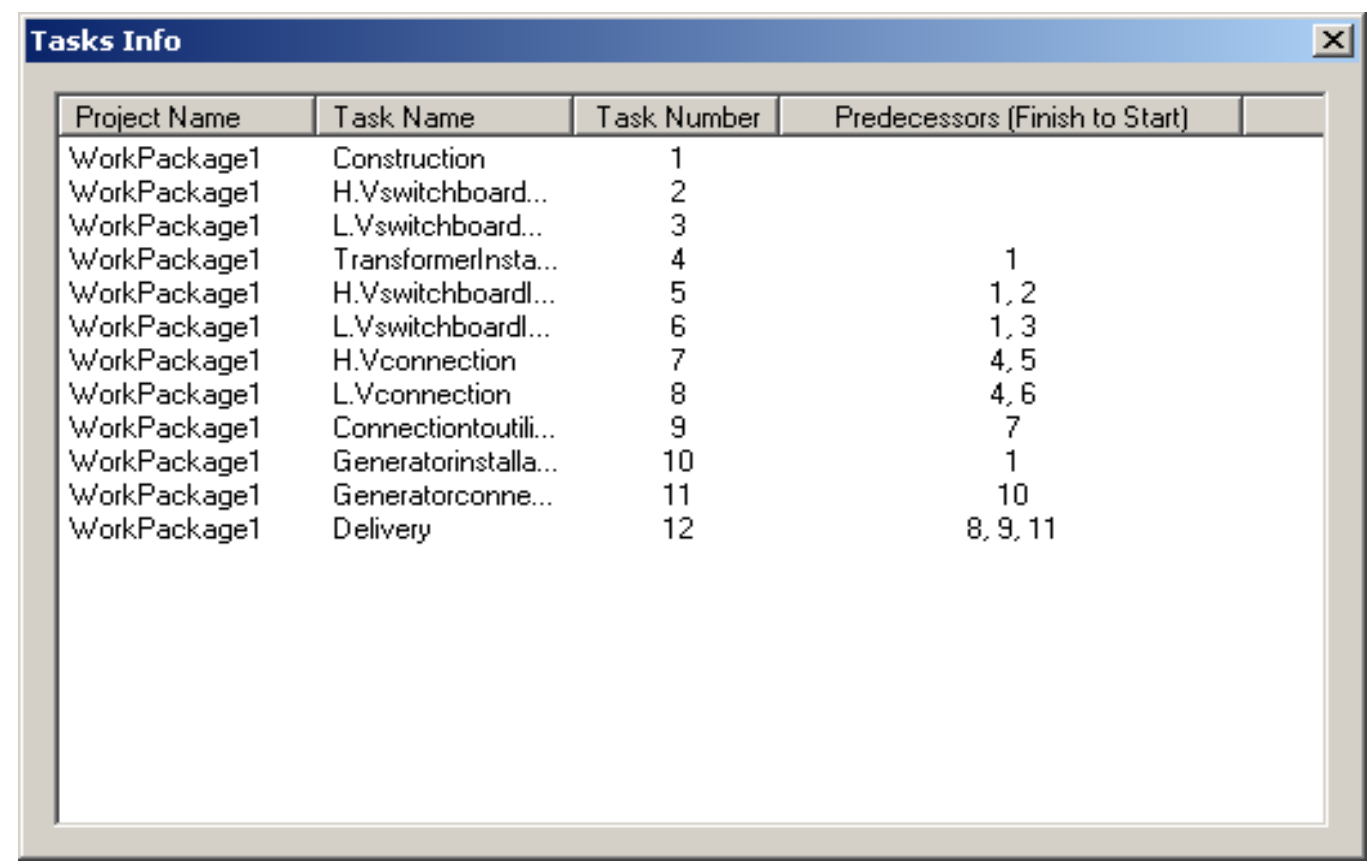

Figure 7: the task information screen for the electric distribution substation project

The cost of these projects includes the cost of resources (per time period and per time period idle), the cost of hiring and firing resources, the fixed cost of tasks according to the selected mode, and a bonus for early completion or a penalty for late completion (see Figure 8):

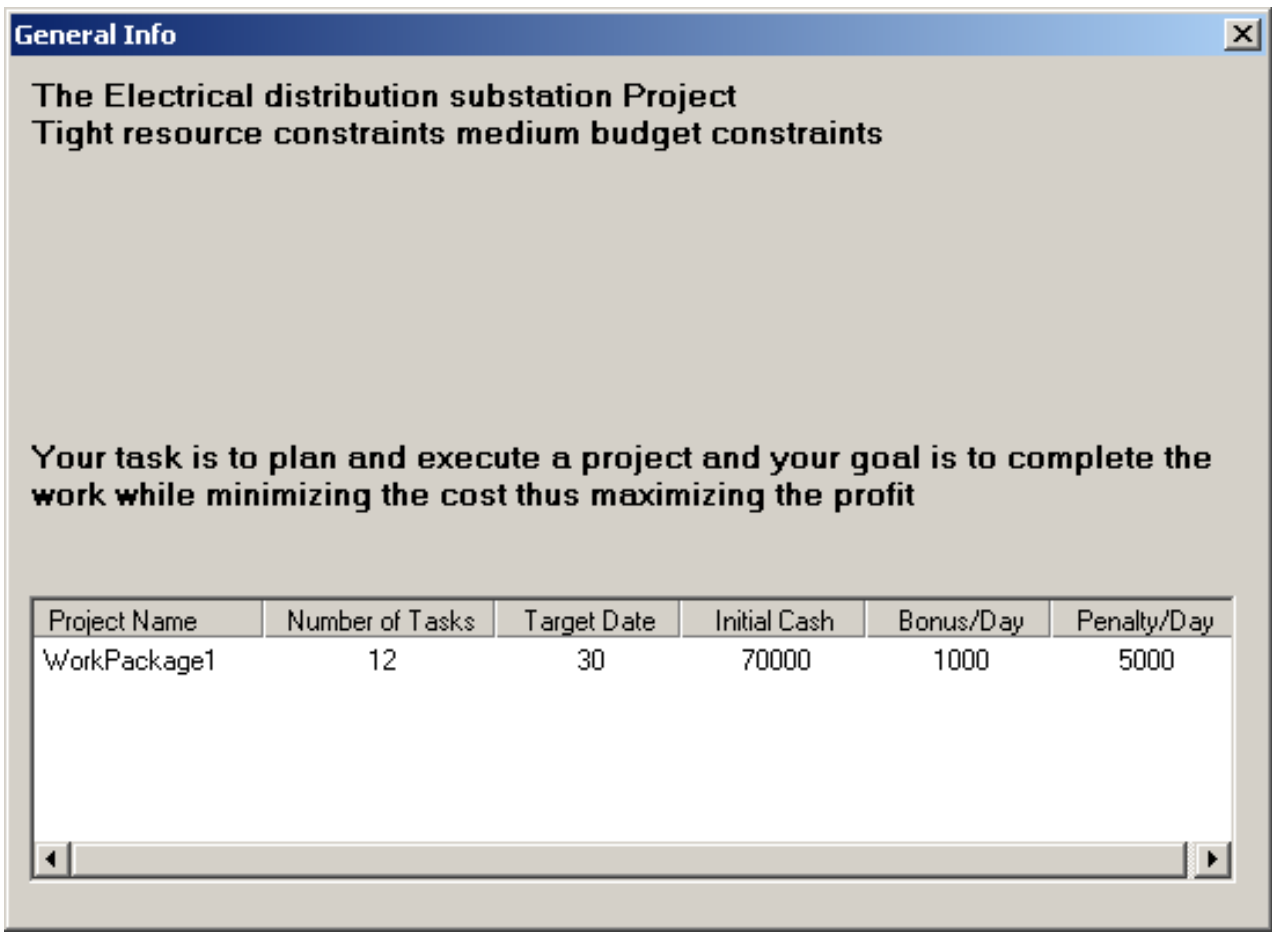

Figure 8: the general information screen for the electric distribution substation project 
In the advanced scenarios the user must pay attention to the trade-offs between the different cost components and to the risk resulting from uncertainty in task duration and in the availability of resources.

Four advanced scenarios are presented. Each scenario is designed to focus on different aspects of project management paying special attention to constraints and uncertainty:

1. Light Resource and Light Budget constraints (LRLB)

2. Light Resource constraints Medium Budget constraint (LRMB)

3. Tight Resource constraints Medium Budget constraints (TRMB)

4. Light Resource constraints Tight Budget constraints. (LRTB)

The four advanced scenarios are not solved in the book "Project management simulation with PTB project team builder" and their solution is left as a challenge to the reader.

\section{REFERENCES}

Alessi, S. M. 1998. Fidelity in the design of instructional simulations. Journal of Computer-Based Instruction 15(2):40-47.

Archer, J.E., R. Conway, and F.B. Schneider. 1984. User recovery and reversal in interactive systems. ACM Transactions on Programming Languages and Systems 6(1):1-19.

Carroll, S., S. Beyerlein, M. Ford, and D. Apple. 1996. The learning assessment journal as a tool for structured reflection in process education. Proceedings of Frontiers in Education'96, IEEE, 310-313.

Cuevas, H.M., S.M. Fiore, C.A. Bowers, and E. Salas. 2004. Fostering constructive cognitive and metacognitive activity in computer-based complex task training environments. Computers in Human Behavior 20:225-241.

Davidovitch, L., A. Parush, and A. Shtub. 2006. Simulation-based learning in engineering education: Performance and transfer in learning project management. Journal of Engineering Education 95(4):289-299.

Davidovitch, L, A. Parush, and A. Shtub. 2008. Simulation-based learning: The learning-forgettingrelearning process and impact of learning history. Computers and Education 50:866-880.

Davidovitch, L, A. Parush, and A. Shtub. 2009. The impact of functional fidelity in simulator-based learning of project management. International Journal of Engineering Education 25(2):333-340.

Grieshop, J. I. 1987. Games: powerful tools for learning. Journal of Extension 25(1).

Guzdial, M., J. Kolodner, C. Hmelo, H. Narayanan, D. Carlso, N. Rappin, R. Hubscher, J. Turns, and W. Newstetter. 1996. The collaboratory notebook. Communications of the ACM 39(4):32-33.

IJEE. 2009. Special issue on Simulators for Engineering Education and for Professional Development. International Journal of Engineering Education 25(2).

Keys, B. 1976. A review of learning research in business gaming. In: Proceedings of the Third Annual Conference of the Association for Business Simulation and Experimental Learning, ABSEL, ed. B. H. Sord.

Kirby. A. 1992. Games for trainers 1. Cambridge: Gower.

Knoppen, D., and M.J. Sáenz. 2007. Supply chain collaboration games: a conceptual model of the gaming process. In: Learning with games, ed. M. Taisch, and J. Cassina. Italy: Mar. Co.

Kolb, D. A. 1984. Experiential learning. England: Prentice Hall.

Meijer, S., G.J. Hofstede, G. Beers, and S.W. Omta. 2006. Trust and tracing game: learning about transactions and embeddedness in a trade network. Production Planning and Control 17(6):569-583.

Millians, D. 1999. Thirty years and more of simulations and games. Simulation \& Gaming 30(3):352355.

Parush, A., H. Hamm, and A. Shtub. 2002. Learning histories in simulation-based teaching: the effects on self-learning and transfer. Computers and Education 39:319-332. 
Prechelt, L. 2001. Accelerating learning from experience: avoiding defects faster. IEEE Software. Nov/Dec:56-61.

Randel, J., B.A. Morris, C.D. Wetzel, and B.V. Whitehill. 1992. The effectiveness of games for educational purposes: a review of recent research. Simulation \& Gaming 23(3):261-276.

Ruben, B.D. 1999. Simulations, games and experience-based learning: the quest for a new paradigm for teaching and learning. Simulation \& Gaming 30(4):498-505.

Shtub, A. 1999. Enterprise resource planning: the dynamics of operations management. Norell, Massachusetts: Kluwer.

Shtub, A. 2001. Teaching operations in the enterprise resource planning (ERP) era. International Journal of Production Research 39(3):567-576.

Shtub, A. 2010. Project Management Simulation with PTB Project Team Builder. New York, New York: Springer.

Available

via

<http://www.springer.com/engineering/production+eng/book/978-1-4419$6462-5>$ [accessed on October 22, 2010]

Smeds, R., and J.O. Riis, eds. 1998. Experimental learning in production management. London: Chapman and Hall.

Thoben, K.D., J.B. Hauge, R. Smeds, and J.O. Riis, eds. 2007. Multidisciplinary research on new methods for learning and innovation in enterprise networks. Aachen: Verlaag Mainz.

Thompson, T.H., J.M. Purdy, and P.M. Fandt. 1997. Building a strong foundation using a computer simulation in an introductory management course. Journal of Management Education 21:418-434.

Vargo, C. G., C. E. Brown, and S. J. Swierenga. 1992. An evaluation of computer-supported backtracking in a hierarchical database. In Proceedings of the Human Factors Society's 36th Annual Meeting:356-360.

Wolfe, J. 1993. A history of business teaching games in English-speaking and post-socialist countries: The origination and diffusion of a management education and development technology. Simulation \& Gaming 24:446-463.

\section{AUTHOR BIOGRAPHY}

AVRAHAM SHTUB is the Stephen and Sharon Seiden Professor of Project Management. He is the recipient of the Institute of Industrial Engineering 1995 "Book of the Year Award" for his Book "Project Management: Engineering, Technology and Implementation" (co-authored with Jonathan Bard and Shlomo Globerson), Prentice Hall, 1994. He is the recipient of the Production Operations Management Society 2000 Wick Skinner Teaching Innovation Achievements Award for his book: "Enterprise Resource Planning (ERP): The Dynamics of Operations Management". Professor Shtub is the recipient of the 2008 Project Management Institute Professional Development Product of the Year Award for the training simulator "Project Team Builder - PTB". More information on PTB and videos are available at $<$ http://www. sandboxmodel.com/>. His books on Project Management have been published in English, Hebrew, Greek and Chinese. Prof. Shtub was a Department Editor for IIE Transactions, he was on the Editorial Boards of the Project Management Journal, The International Journal of Project Management, IIE Transactions and the International Journal of Production Research. His email address is <shtubie.technion.ac.ils and his website is <http://ie.technion.ac.il/Home/Users/shtubo.html>. 